\title{
Pengaruh Customer Relationship Management Dan Kepuasan Terhadap Loyalitas Anggota
}

(Studi Pada BUMDes se-Kecamatan Penebel, Tabanan)

\author{
I Wayan Suartina ${ }^{(1)}$ \\ Anak Agung Ngurah Sadiartha ${ }^{(2)}$ \\ Ni Nyoman Rahayu Diantari Ady ${ }^{(3)}$ \\ (1)(2)(3)Fakultas Ekonomi Bisnis dan Pariwisata Universitas Hindu Indonesia \\ e-mail:wynsuartina@gmail.com; rahayu.diantariady@yahoo.com \\ \begin{tabular}{|l|l|l}
\hline Diterima: 31 Juli 2020 & Direvisi: 10 Agustus 2020 & Disetujui: 18 Agustus 2020
\end{tabular}
}

\begin{abstract}
The purpose of this study was to determine the effect of customer relationship management on member satisfaction, the effect of member satisfaction on member loyalty, the effect of customer relationship management on member loyalty, and the influence of customer relationship management on loyalty which is influenced by member satisfaction. This research was conducted at Village-Owned Enterprises (BUMDes) throughout Penebel District, Tabanan, Bali with a sample of 100 people who were determined using the Slovin method and the determination of the sample using incidental sampling. Testing instruments and analysis tools include validity test, reliability test, and path analysis accompanied by Sobell test. Based on the results of the path analysis test, it was found that customer relationship management has a positive and significant effect on member satisfaction, member satisfaction has a positive and significant effect on member loyalty, customer relationship management has a positive and significant effect on member loyalty and based on the results of the Sobell test, member satisfaction has been proven. mediating the relationship between the influence of customer relationship management on member loyalty is seen from the value of Z-score (4.84)> Z-table (1.66). Suggestions given in this study are BUMDes in Penebel District are suggested to further improve customer relationship management strategies to increase member satisfaction and loyalty from members.
\end{abstract}

Keywords: Customer Relationship Management, member satisfaction, member loyalty

\section{Pendahuluan}

Pemerintah Desa untuk meningkatkan pemberdayaan masyarakat desa adalah dengan mendirikan Badan Usaha Milik Desa (BUMDes) (UU Nomor 6 Tahun 2014), karena dengan adanya BUMDes diharapkan mampu mendorong desa untuk mengelola sumber daya yang ada di desa, termasuk pengembangan ekonomi masyarakat desa. Menurut pengertian yang dimaksud dalam perundangan yang berlaku (UU Desa), BUMDes adalah badan usaha yang seluruh atau sebagian besar modalnya dimiliki desa. Berdasarkan pengertian tersebut, BUMDes merupakan badan usaha bukan badan sosial ataupun badan amal. Tujuan BUMDes yaitu untuk kesejahteraan 
masyarakat desa, sehingga BUMDes harus menghasilkan profit dan benefit. Kesusksesan BUMDes tidak hanya diukur melalui profit, tetapi juga kebermanfaatannya bagi kehidupan masyarakat desa.

Saat ini sudah banyak BUMDes yang sudah berkembang dan membantu masyarakat, baik dalam peminjaman dana atau pengembangan usaha desa sehingga memiliki sumber dana lain tak hanya melalui LPD. Sehingga harapan pemerintah pusat adalah membentuk desa yang mandiri dengan mengelola dengan baik SDM dan SDA yang ada di desa melalui BUMDes. Kecamatan Penebel saat ini juga mengembangkan BUMDes ke tahap yang lebih tinggi dan berusaha untuk membentuk desa yang mandiri.

Pengelolaan operasional BUMDes harus memiliki daya inovasi dan kreativitas untuk menciptakan sesuatu yang baru dan berbeda. Untuk mengedepankan pendekatan bisnis dari pihak BUMDes harus menerapkan salah satu manajemen hubungan untuk secara seksama memaksimalkan kualitas dan loyalitas dari anggota maka perlu menerapkan Customer Relationship Management (CRM). Kotler dan Lupiyoadi (2003:228) menyebutkan bahwa faktor penting dalam penerapan CRM adalah kualitas pelayanan yang dapat dilihat dari pencapaian kepuasan pelanggan.

BUMDes harus meningkatkan kualitas proses pelayanan, baik dari segi SDM atapun teknologi yang itu merupakan faktor-faktor dari penerapan CRM sehingga anggota BUMDes merasa puas dan setia terhadap perusahaan. Menurut Barnes (2003) dasar dari loyalitas merupakan penunjang dalam kepuasan anggota. Untuk meningkatkan loyalitas, maka harus meningkatkan tingkat kepuasan setiap anggota dalam jangka panjang. Sesuai dengan tujuan awal dari BUMDes yaitu penguatan ekonomi desa dan tentu saja hal utama yang penting adalah memperkuat kerjasama, membangun kebersamaan/ menjalin kerekatan dan hubungan dengan anggota BUMDes dan tentu saja dengan semua lapisan masyarakat desa. Berdasarkan fenomena yang ditemukan peneliti di BUMDes se-Kecamatan Penebel, Kab, Tabanan peneliti akan menguji kembali model Pengaruh CRM (Customer Relationsip Management) terhadap loyalitas anggota yang dipengaruhi oleh kepuasan anggota.

Penelitian ini bertujuan untuk mengetahui pengaruh Customer Relationship Management (CRM) dan kepuasan anggota terhadap lepuasan anggota di BUMDes se-Kecamatan Penebel.

\section{Telaah Literatur dan Kajian Pustaka}

Kotler dan Keller (2006:6) menjelaskan bahwa manajemen pemasaran merupakan suatu seni dan ilmu memilih pasar sasaran dan mendapatkan, mempertahankan, dan menumbuhkan pelanggan dengan melalui penciptaan, penyampaian, dan pengkomunikasian nilai pelanggan 
superior. Menurut Plessis \& Boom (2004) dikutip dalam Tjiptono (2014:424) customer relationship management (CRM) merupakan suatu proses membangun dan mengelola relasi dengan pelanggan dalam level organisasional dengan jalan memahami, mengantisipasi dan mengelola kebutuhan pelanggan berdasarkan pengetahuan yang didapatkan mengenai pelanggan, dalam rangka maningkatkan efektivitas, efesiensi, dan profitabilitas dari organisasi. Dalam penelitian (Gifano, 2012) yang mengutip pendapat dari Lukas (2001) yang mengatakan bahwa keberhasilan CRM ditentukan oleh tiga komponen utama, yaitu a) Manusia (Sumber Daya Manusia); b) Proses; dan c) Teknologi.

Menurut Kotler dan Keller (2007:177), kepuasan adalah perasaan senang atau kecewa seseorang yang muncul setelah membandingkan kinerja produk yang diperkirakan terhadap kerja (hasil) yang diharapkan. Zeithaml dan Bitner (2003) mengemukakan bahwa, kepuasan adalah konsep yang jauh lebih luas dari hanya sekedar penilaian kualitas pelayanan. Indikator dari kepuasan menurut Zeithaml dan Bitner (2003) adalah kualitas pelayanan (service performance), kualitas produk, harga, faktor situasi, faktor pribadi. Menurut Tjiptono (2000:110) loyalitas pelanggan adalah komitmen pelanggan terhadap suatu merek, toko atau pemasok berdasarkan sikap yang sangat positif dan tercermin dalam pembelian ulang yang konsisten. Indikator loyalitas anggota menurut Griffin (2005:51 adalah melakukan pembelian berulang secara teratur, membeli antar lini produk barang dan jasa, merekomendasikan produk kepada orang lain (refers other), dan menunjukan kekebalan terhadap tarikan dari pesaing.

Kotler dan Armstrong (2004:13) menyatakan bahwa proses penciptaan, pemeliharaan dan penguatan hubungan yang kuat dan penuh nilai dengan pelanggan dan pemercaya. Faktor yang salah satunya mempengaruhi kepuasan anggota adalah Customer Realtionship Management (CRM) yaitu bagaimana cara perusahaan dalam membangun hubungan atau relasi yang baik sehingga menciptakan kepuasan. Victor dkk. (2015) menyatakan hasil bahwa customer relationship management berpengaruh secara signifikan terhadap kepuasan anggota. customer relationship management mampu mempengaruhi kepuasan anggota dikarenakan hubungan yang dibuat oleh perusahaan agar anggota tidak berpindah pada merek ataupun perusahaan lain.

H1: Diduga Customer Relationship Management berpengaruh positif dan signifikan terhadap kepuasan anggota di BUMDes se-Kecamatan Penebel.

Pelanggan yang merasa puas berkepanjangan akan menghasilkan loyalitas terhadap BUMDes dan meningkatkan keuntungan dari BUMDes itu sendiri. Tjiptono (2000:110) menyebutkan bahwa loyalitas pelanggan adalah sebagai komitmen pelanggan terhadap suatu merek, toko, pemasok berdasarkan sikap yang sangat positif dan tercermin dalam pembelian ulang yang konsisten. Menurut Aswan (2013) dalam pembentukan loyalitas anggota maka yang 
dibutuhkan adalah dengan menciptakan kepuasan dari anggota yang berkepanjangan. Oleh karena itu, memiliki anggota yang puas dan loyal menjadi prioritas dan strategi utama para pemasar. Putri dan Purnami (2019) menyatakan bahwa kepuasan pelanggan berpengaruh positif secara langsung terhadap loyalitas pelanggan.

H2: Diduga kepuasan anggota berpengaruh positif dan signifikan terhadap loyalitas anggota di BUMDes se-Kecamatan Penebel.

Loyalitas anggota dapat diperoleh dengan menerapkan strategi CRM. Menurut Buchari (2010:296) customer relationship management adalah suatu proses mendapatkan, mempertahankan dan meningkatkan hubungan dengan pelanggan yang menguntungkan dengan tujuan untuk menciptakan nilai pelanggan sehingga pelanggan puas dan memaksimalkan keuntungan bagi perusahaan dalam rangka memperoleh keunggulan bersaing (competitive advantage). Rindang dkk. (2016) menyatakan bahwa CRM berpengaruh positif dan signifikan terhadap loyalitas anggota. Menciptakan hubungan yang kooperatif tersebut maka akan terjalinnya loyalitas yang kuat sehingga membuat kedua belah pihak akan saling mendapatkan keuntungan.

H3: Diduga Customer Relationship Management berpengaruh positif dan signifikan terhadap loyalitas anggota di BUMDes se-Kecamatan Penebel.

Customer relationship management mempunyai peranan dalam mempengaruhi kepuasan anggota sehingga berujung dalam menciptakan loyalitas anggota. Menurut Permadi (2013); dan Silvia et al. (2015) bahwa kepuasan dapat menjadi variabel mediasi yang berpengaruh kuat dalam mempengaruhi loyalitas dari anggota. Konsep utama dari customer relationship management yaitu upaya perusahaan untuk mewujudkan nilai bagi para pelanggan sehingga mampu memahami, mengantisipasi dan mengelola kebutuhan pelanggan dengan tujuan untuk memberikan kepuasan dan membangun hubungan jangka panjang. Putri dan Purnami (2019) menyatakan bahwa customer relationship management memiliki pengaruh secara tidak langsung terhadap loyalitas pelanggan melalui kepuasan sebagai variabel intervening.

H4: Diduga Customer Relationship Management berpengaruh positif dan signifikan terhadap loyalitas anggota yang dipengaruhi oleh kepuasan anggota di BUMDes se-Kecamatan Penebel.

\section{Metode Penelitian}

Penelitian dilakukan di BUMDes se-Kecamatan Penebel, Kabupaten Tabanan, Bali, Indonesia dan objek penelitiannya adalah customer relationship management, kepuasan anggota dan loyalitas anggota. Populasi dalam penelitian ini adalah keseluruhan anggota di BUMDes seKecamatan Penebel secara aktif (anggota aktif) dimana anggota BUMDes adalah masyarakat di 
desa tersebut. Jadi pada penelitian ini jumlah populasi dari 13 BUMDes yang ada di Kecamatan Penebel sebanyak 650 orang. Responden ditentukan dengan menggunakan rumus slovin dengan jumlah sebanyak 100 responden. Penentuan sampel dalam penelitian ini dilakukan dengan metode insidental sampling, responden dipilih berdasarkan anggota BUMDes secara kebetulan datang ke BUMDes di daerah Penebel atau yang sedang melakukan transaksi baik berupa simpan pinjam, berbelanja maupun transaksi lain.

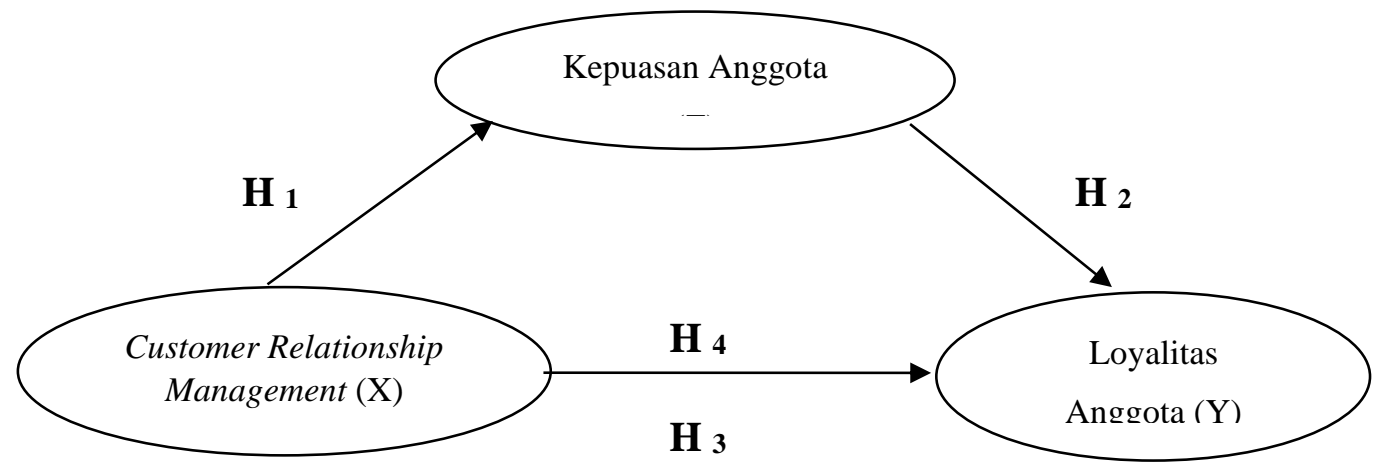

Gambar 1. Kerangka Berpikir Penelitian

\section{Hasil Penelitian dan Pembahasan}

Tabel 1. Karakteristik Frekuensi Responden

\begin{tabular}{|c|c|c|c|c|}
\hline No. & Variabel & Klasifikasi & Jumlah Orang & Persentase $(\%)$ \\
\hline 1 & $\begin{array}{c}\text { Jenis Kelamin } \\
\text { Jumlah }\end{array}$ & $\begin{array}{l}\text { Laki-Laki } \\
\text { Perempuan }\end{array}$ & $\begin{array}{c}45 \\
55 \\
\mathbf{1 0 0}\end{array}$ & $\begin{array}{c}45 \% \\
55 \% \\
100 \%\end{array}$ \\
\hline 2 & $\begin{array}{c}\text { Usia } \\
\text { Jumlah }\end{array}$ & $\begin{array}{c}22-31 \text { Tahun } \\
32-41 \text { Tahun } \\
42-51 \text { Tahun } \\
>52 \text { Tahun }\end{array}$ & $\begin{array}{c}8 \\
38 \\
38 \\
16 \\
\mathbf{1 0 0}\end{array}$ & $\begin{array}{c}8 \% \\
38 \% \\
38 \% \\
16 \% \\
\mathbf{1 0 0 \%}\end{array}$ \\
\hline 3 & $\begin{array}{c}\text { Pendidikan } \\
\text { Jumlah }\end{array}$ & $\begin{array}{c}\text { SD } \\
\text { SMP } \\
\text { SMA/SMK } \\
\text { Diploma } \\
\text { S1 } \\
\text { S2 }\end{array}$ & $\begin{array}{c}6 \\
20 \\
57 \\
16 \\
1 \\
- \\
\mathbf{1 0 0}\end{array}$ & $\begin{array}{c}6 \% \\
20 \% \\
57 \% \\
16 \% \\
1 \% \\
- \\
\mathbf{1 0 0 \%}\end{array}$ \\
\hline 4 & Pekerjaan & $\begin{array}{c}\text { PNS } \\
\text { Swasta } \\
\text { Wiraswasta } \\
\text { TNI/POLRI } \\
\text { Lain-lain }\end{array}$ & $\begin{array}{c}1 \\
13 \\
48 \\
- \\
38 \\
\mathbf{1 0 0} \\
\end{array}$ & $\begin{array}{c}1 \% \\
13 \% \\
48 \% \\
- \\
38 \% \\
100 \% \\
\end{array}$ \\
\hline
\end{tabular}

Sumber: data diolah, 2020 
Berdasarkan pada tabel 1 jumlah responden perempuan lebih banyak, untuk usia responden pada usia 32-41 tahun dan 42-51 tahun. Sebagian besar pendidikan terakhir adalah SMA/SMK dan mayoritas responden bekerja sebagai wiraswasta.

\section{Tabel 2. Hasil Uji Validitas}

\begin{tabular}{|c|c|c|c|c|}
\hline No & Variabel & Indikator & Koefisien Korelasi & Keterangan \\
\hline \multirow[t]{6}{*}{1} & \multirow{6}{*}{$\begin{array}{l}\text { Customer } \\
\text { Relationship } \\
\text { Management (X) }\end{array}$} & $\mathrm{X} 1$ & 0,926 & VALID \\
\hline & & $\mathrm{X} 2$ & 0,896 & VALID \\
\hline & & $\mathrm{X} 3$ & 0,906 & VALID \\
\hline & & $\mathrm{X} 4$ & 0,922 & VALID \\
\hline & & X5 & 0,824 & VALID \\
\hline & & X6 & 0,860 & VALID \\
\hline \multirow[t]{6}{*}{2} & \multirow{6}{*}{ Kepuasan (Z) } & $\mathrm{Z} 1$ & 0,914 & VALID \\
\hline & & Z2 & 0,895 & VALID \\
\hline & & Z3 & 0,832 & VALID \\
\hline & & Z4 & 0,868 & VALID \\
\hline & & Z5 & 0,888 & VALID \\
\hline & & Z6 & 0,878 & VALID \\
\hline \multirow[t]{5}{*}{3} & \multirow{5}{*}{ Loyalitas (Y) } & Y1 & 0,922 & VALID \\
\hline & & Y2 & 0,886 & VALID \\
\hline & & Y3 & 0,957 & VALID \\
\hline & & Y4 & 0,928 & VALID \\
\hline & & Y5 & 0,846 & VALID \\
\hline
\end{tabular}

Sumber: data diolah, 2020

Berdasarkan hasil uji validitas diatas menunjukan seluruh indikator penelitian dikatakan valid yaitu nilai korelasi di atas 0,30 (>30) dan layak dilanjutkan ke analisis berikutnya.

Tabel 3. Hasil Uji Reliabilitas

\begin{tabular}{|c|c|c|c|}
\hline No & Variabel & $\begin{array}{c}\text { Cronbach's } \\
\text { Alpha }\end{array}$ & Keterangan \\
\hline 1 & Customer Relationship Management (X) & 0,947 & Reliabel \\
\hline 2 & Kepuasan $(\mathrm{Z})$ & 0,941 & Reliabel \\
\hline 3 & Loyalitas (Y) & 0,947 & Reliabel \\
\hline
\end{tabular}

Sumber : data primer, 2020

Berdasarkan hasil uji reliabilitas diatas, menunjukan bahwa seluruh instrumen penelitian dikatakan reliabel dimana seluruh instrumen layak digunakan untuk mengumpulkan data yaitu nilai Cronbach's Alpha $>0,70$.

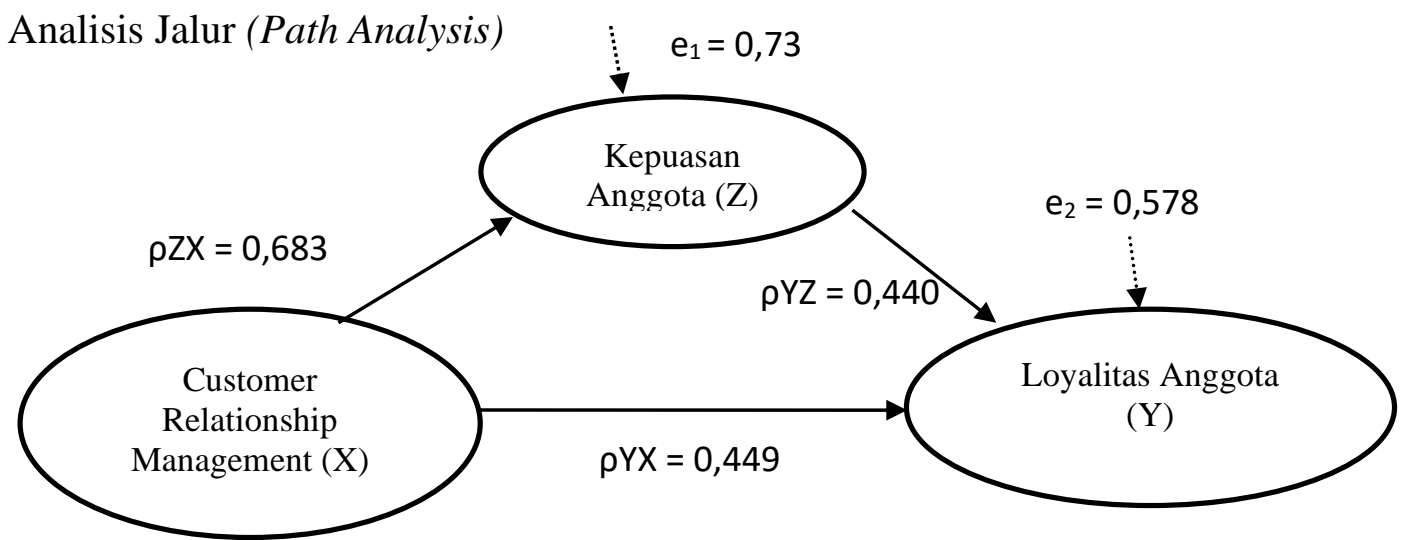

Gambar 2. Model Jalur 
Tabel 4. Coefficients Sub Struktur 1 (Model 1)

\begin{tabular}{|c|c|c|c|c|c|c|}
\hline \multicolumn{7}{|c|}{ Coefficients $^{\mathrm{a}}$} \\
\hline \multirow{2}{*}{\multicolumn{2}{|c|}{ Model }} & $\begin{array}{r}\text { Unsta } \\
\text { Coe }\end{array}$ & $\begin{array}{l}\text { dardized } \\
\text { cients }\end{array}$ & $\begin{array}{l}\text { Standardized } \\
\text { Coefficients }\end{array}$ & $t$ & Sig. \\
\hline & & $B$ & Std. Error & Beta & & \\
\hline \multirow{2}{*}{1} & (Constant) & 9.301 & 1.549 & & 6.003 & .000 \\
\hline & CRM & .609 & .066 & .683 & 9.245 & .000 \\
\hline
\end{tabular}

a. Dependent Variable: Kepuasan

Sub Struktur 1:

$\mathrm{Z}=\beta_{1} \mathrm{X}+\mathrm{e}_{1}$

Tabel 5. Coefficients Sub Struktur 2 (Model 2)

Coefficients $^{a}$

\begin{tabular}{|c|c|c|c|c|c|c|}
\hline \multirow[t]{2}{*}{ Model } & & \multicolumn{2}{|c|}{$\begin{array}{c}\text { Unstandardized } \\
\text { Coefficients }\end{array}$} & \multirow{2}{*}{$\begin{array}{c}\text { Standardize } \\
d \\
\text { Coefficients } \\
\text { Beta }\end{array}$} & \multirow[t]{2}{*}{$\mathrm{t}$} & \multirow[t]{2}{*}{ Sig. } \\
\hline & & $B$ & Std. Error & & & \\
\hline \multirow{3}{*}{1} & (Constant) & 2.053 & 1.309 & & 1.568 & .120 \\
\hline & CRM & .363 & .065 & .449 & 5.578 & .000 \\
\hline & Kepuasan & .399 & .073 & .440 & 5.467 & .000 \\
\hline
\end{tabular}

a. Dependent Variable: Loyalitas

Sub Struktur 2

$Z=\beta_{1} X+\beta_{2} Z+e_{2}$

Tabel 6. Pengaruh Langsung, Pengaruh Tidak Langsung dan Pengaruh Total Variabel Customer Relationship Management, Kepuasan Anggota dan Loyalitas Anggota.

\begin{tabular}{llccc}
\hline \multicolumn{2}{c}{ Variabel } & $\begin{array}{c}\text { Pengaruh } \\
\text { Langsung }\end{array}$ & $\begin{array}{c}\text { Pengaruh Tidak } \\
\text { Langsung melalui } \\
\text { Kepuasan }\end{array}$ & $\begin{array}{c}\text { Pengaruh } \\
\text { Total }\end{array}$ \\
\hline $\begin{array}{l}\text { Customer } \\
\text { Relationship } \\
\text { Management }\end{array}$ & $\begin{array}{l}\text { Kepuasan } \\
\text { Anggota }\end{array}$ & 0,683 & - & 0,683 \\
Kepuasan Anggota & $\begin{array}{l}\text { Loyalitas } \\
\text { Anggota }\end{array}$ & 0,440 & - & 0,440 \\
$\begin{array}{l}\text { Customer } \\
\text { Relationship } \\
\text { Management }\end{array}$ & Aoyalitas & 0,449 & 0,578 & 1,027 \\
\hline
\end{tabular}

Sumber : data primer diolah, 2020

a. Hasil koefisien determinasi total:

$\mathrm{R}_{\mathrm{m}}^{2}=0,82$

Ini berarti keragaman data oleh model adalah sebesar $82 \%$ atau dengan kata lain informasi yang terkandung dalam data sebesar $82 \%$ dapat dijelaskan oleh model, sedangkan sisanya $18 \%$ dijelaskan oleh variabel lain. 


\section{b. $\quad$ Theory Trimming}

Nilai $\rho$ dari uji t yaitu pengujian koefisien regresi variabel dibakukan secara parsial dengan customer relatiosnhip management $(\mathrm{X})$ terhadap kepuasan anggota $(\mathrm{Z})$ adalah 9,245 Sig. 0,000, customer relatiosnhip management $(\mathrm{X})$ terhadap loyalitas anggota (Y) adalah 5,578 dengan Sig. 0,000, variabel kepuasan naggota (Z) terhadap loyalitas anggota (Y) sebesar 5,467 dengan Sig. 0,000.

Untuk menguji variabel mediator yang memediasi hubungan antara variabel terikat dengan variabel bebas dapat disimpulan bahwa variabel kepuasan anggota dapat memediasi hubungan antara Customer Relationship Management dengan loyalitas anggota karena $\mathrm{Z}$ hitung lebih besar

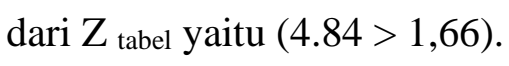

Berdasarkan hasil perhitungan dapat diperoleh taraf signifikansi penelitian variabel customer relationship management terhadap kepuasan anggota sebesar $0,000<0,05$, sehingga $\mathrm{H}_{0}$ ditolak dan $\mathrm{H}_{1}$ diterima, dengan kata lain hipotesis pertama, customer relationship management berpengaruh positif dan signifikan terhadap kepuasan anggota pada BUMDes se-Kecamatan Penebel dapat diterima. Berdasarkan hasil perhitungan taraf signifikansi penelitian variabel kepuasan anggota terhadap loyalitas anggota sebesar $0,000<0,05$, sehingga $\mathrm{H}_{0}$ ditolak dan $\mathrm{H}_{2}$ diterima, dengan kata lain hipotesis kedua, kepuasan anggota berpengaruh positif dan signifikan terhadap loyalitas anggota pada BUMDes se-Kecamatan Penebel dapat diterima. Hasil perhitungan diperoleh taraf signifikansi penelitian untuk variabel Customer Relationship Management terhadap loyalitas anggota sebesar $0,000<0,05$, sehingga $\mathrm{H}_{0}$ ditolak dan $\mathrm{H}_{3}$ diterima, berarti hipotesis ketiga, Customer Relationship Management berpengaruh positif dan signifikan terhadap loyalitas anggota di BUMDes se-Kecamatan Penebel dapat diterima. Berdasarkan hasil perhitungan diperoleh taraf $\mathrm{t}$ hitung $(4.84)>\mathrm{t}$ tabel $(1,66)$ dengan nilai signifikansi $0,000<0,05$, sehingga $\mathrm{H}_{0}$ ditolak dan $\mathrm{H}_{4}$ diterima. Dengan demikian kepuasan anggota BUMDes se-Kecamatan Penebel terbukti dapat memediasi hubungan antara Customer Relationship Management dengan loyalitas anggota di BUMDes se-Kecamatan Penebel dapat diterima.

1. Pengaruh Customer Relationship Management Terhadap Kepuasan Anggota Pada BUMDes se-Kecamatan Penebel

Berdasarkan hasil uji emperik didapatkan taraf signifikansi penelitia variabel customer relatiosnhip management terhadap kepuasan anggota sebesar $0,000<0,05$, sehingga Ho ditolak dan $\mathrm{H}_{1}$ diterima yang berarti customer relatiosnhip management berpengaruh signifikan terhadap kepuasan anggota di BUMDes se-Kecamatan Penebel. Hasil penelitian ini menunjukkan bahwa customer relationship management vang diterapkan BUMDes se-Kecamatan Penebel mampu memberikan hubungan yang baik dengan anggotanya. Penelitian ini sejalan dengan penelitian 
Victor dkk. (2015) yang menunjukkan hasil bahwa customer relationship management memiliki pengaruh yang signifikan terhadap kepuasan anggota. customer relationship management mempengaruhi kepuasan anggota dikarenakan hubungan yang dibuat oleh perusahaan agar anggota tidak berpindah pada merek ataupun perusahaan lain.

2. Pengaruh Kepuasan Anggota Terhadap Loyalitas Anggota Pada BUMDes se-Kecamatan Penebel

Berdasarkan hasil uji emperik didapatkan taraf signifikansi penelitian untuk variabel kepuasan anggota terhadap loyalitas anggota sebesar 0,000 < 0,05. sehingga Ho ditolak dan $\mathrm{H}_{2}$ diterima yang berarti variabel kepuasan anggota berpengaruh signifikan terhadap loyalitas anggota pada BUMDes se-Kecamatan Penebel. Penelitian ini sejalan dengan penelitian yang dilakukan oleh Putri dan Purnami (2019) yang mengemukakan bahwa kepuasan pelanggan berpengaruh positif secara langsung terhadap loyalitas pelanggan. Apabila kepuasan pelanggan meningkat, maka loyalitas pelanggan tentu akan meningkat pula dan sebaliknya apabila kepuasan pelanggan menurun, maka loyalitas pelanggan tentu akan menurun.

3. Pengaruh Customer Relationship Management Terhadap Loyalitas Anggota pada BUMDes se-Kecamatan Penebel

Berdasarkan hasil uji emperik didapatkan taraf signifikansi penelitian untuk variabel customer relationship management terhadap loyalitas anggota sebesar 0,000 < 005, sehingga Ho ditolak dan $\mathrm{H}_{3}$ diterima yang berarti bahwa customer relationship management berpengaruh signifikan terhadap loyalitas anggota pada BUMDes se-Kecamatan Penebel. Penelitian ini juga sejalan dengan penelitian yang dilakukan oleh Rindang dkk. (2016) yang mengemukakan bahwa CRM berpengaruh positif dan signifikan terhadap loyalitas anggota. Menciptakan hubungan yang kooperatif tersebut maka akan terjalin loyalitas yang kuat sehingga kedua belah pihak akan saling mendapatkan keuntungan.

4. Pengaruh Customer Relationship Management Terhadap Loyalitas Anggota Melalui Mediasi Kepuasan Anggota Pada BUMDes se-Kecamatan Penebel.

Berdasarkan hasil perhitungan yang melalui uji sobel diperoleh hasil $\mathrm{Z}_{\text {hitung }}(4.84)>\mathrm{Z}_{\text {tabel }}$ $(1,66)$ dengan signifikansi $0,000<0,05$, sehingga Ho ditolak dan Ha diterima yang berarti kepuasan anggota terbukti dapat memediasi hubungan antara customer relationship management dengan loyalitas anggota di BUMDes se-Kecamatan Penebel. Hasil penelitian ini sejalan dengan penelitian yang dilakukan oleh Putri dan Purnami (2019) yang menyatakan bahwa customer relationship management berpengaruh secara tidak langsung terhadap loyalitas pelanggan melalui kepuasan sebagai variabel intervening. Ini artinya bahwa variabel kepuasan terbukti dapat 
memediasi serta memperkuat hubungan antara customer relationship management dengan loyalitas anggota.

\section{Simpulan}

Customer Relationship Management (CRM) berpengaruh secara positif dan signifikan terhadap kepuasan anggota di BUMDes se-Kecamatan Penebel. Hal ini menunjukkan bahwa customer relationship management semakin meningkat maka akan meningkatkan pula kepuasan anggota. Kepuasan anggota berpengaruh positif dan signifikan terhadap loyalitas anggota di BUMDes se-Kecamatan Penebel. Ini menunjukan bahwa jika kepuasan anggota meningkat maka akan meningkatkan pula loyalitas anggota. Customer relationship management (CRM) berpengaruh secara positif dan signifikan terhadap loyalitas anggota di BUMDes se-Kecamatan Penebel. Ini menunjukan bahwa customer relationship management semakin meningkat maka akan meningkatkan pula loyalitas anggota. Kepuasan anggota berpengaruh secara positif dan signifikan dalam memediasi pengaruh customer relationship management terhadap loyalitas anggota.

Memberikan komitmen dalam pelayanan akan meningkatkan hubungan dan relasi yang baik antara BUMDes dan anggotanya. BUMDes dapat mempertahankan dan meningkatkan kepuasan anggota yaitu dengan meningkatkan kualitas pelayanan dari karyawan atau perangkat BUMDes itu sendiri sehingga anggota dapat percaya dan merasa puas dengan pelayanan yang diberikan. Cara mempertahankan dan menjaga loyalitas anggota adalah dengan memberikan kualitas produk yang baik secara berkesinambungan dan terus menerus agar anggota tetap melakukan pembelian produk secara berualng dan teratur. Sehingga tingkat loyalitas dari anggota meningkat dan senantiasa memberikan kesan positif tentang BUMDes.

\section{Daftar Pustaka}

Angga, Dwi Permadi, 2013. Pengaruh Penerapan Sistem Akuntansi Keuangan Pemda terhadap Kualitas Laporan Keuangan Pemerintah Daerah, Bandung.

Arikunto, S.2006. Prosedur Penelitian: Suatu Pendekatan Praktik. Jakarta: Rineka Cipta , S. 2013. Prosedur Penelitian: Suatu Pendekatan Praktik. Jakarta: Rineka Cipta

Barnes, James G. 2003. Secrets of Customer Relationship Management. Alih Bahasa: Andreas Winardi. Yogyakarta: Andi

Banker, et al. 2002. Research Metohod in Clinical Psychology. Jhon Wiley \& Sons Ltd. England Buchari, Alma. 2004. Manajemen Pemasaran dan Pemasaran Jasa. Edisi Revisi, Bandung: CV. Alfabeta

Buttle, Francis. 2007. Customer Relationship Management: Manajemen Hubungan Pelanggan Concept and Tools, penerjemah : Arief Subiyanto, Jakarta: PT. Bayumedia 
Dinas Pemberdayaan Masyarakat dan Desa Kabupaten Tabanan 2019. Data Badan Usaha Milik Desa (BUMDES)/ BUMADES Periode 19 Sep 2019

Downey, David. 2002, Manajemen Agribisnis, Buku Keempat Erlangga, Jakarta.

Ega Riantama. 2018. Pengaruh CRM (Customer Relationship Marketing) Terhadap Loyalitas Nasabah Melalui Mediasi Kepuasan Nasabah Pada PT. Sun Life Financial Indonesia di Kuta Selatan. Skripsi Sarjana Jurusan Manajemen Universitas Hindu Indonesia.

Indah Parwati. 2017. Peran Customer Relationship Management (CRM) Memediasi Pengaruh Kualitas Pelayanan Terhadap Loyalitas Konsumen Pada Pt. Orindo Alam Ayu (Oriflame) Cabang Denpasar. Skripsi Sarjana Jurusan Manajemen Universitas Hindu Indonesia.

Griffin, Jill. 2005. Customer Loyalty: Menumbuhkan dan Mepertahankan Kesetiaan Pelanggan.

Jakarta : Penerbit Erlangga.

Hair, et al,2010. Multivariate Data Analysis With Readings, Eanglewoods Cliffs, NJ : Prentice Hall Inc.

Hasan, Ali. 2013. Marketing dan Kasus-kasus Pilihan. Yogyakarta: CAPS.

Khairil, Aswan. (2013). Pengaruh Kepuasan Nasabah Atas Dimensi Kualitas Pelayanan Terhadap Loyalitas Nasabah Tabungan Sikoci Pada Bank Nagari Cabang Lubuk Sikaping. Jurnal Manajemen. Vol.2.No1. Fakultas Ekonomi Universitas Negeri Padang. Kotler, Philip. Manajemen Pemasaran : Analisa Perencanaan, Implementasi dan Kontrol, Edisi Milenium. PT. Prenhalindo, Jakarta, 2002, Hal.38.

Philip, 2003, Manajemen Pemasaran, Edisi Milenium 2, Prenhallindo, Jakarta.

, Philip dan Amstrong, 2004. Dasar-dasar Pemasaran. Edisi kesembilan. Jakarta: PT. Indeks

Philip dan Keller. 2007. Manajemen Pemasaran. Jilid I. PT. Indeks. Jakarta

Philip dan Kevin Lane Keller. 2009. Manajemen Pemasaran. Edisi ke-13. Jakarta: Erlangga.

Rindang Imega Nanda Pertiwi dan Amin Taufiq Kurniawa, (2016) Analisis Pendekatan Customer

Relationship Management Dalam Upaya Membangun Loyalitas Pengguna Di UPT Perpustakaan Muhammadiyah Surakarta.

Peppers, Don and Martha Rogers, 2004. Managing Customer Relationship: a Strategic Framework. New Jersey: Jhon Wiley \& Sons, Inc.

Putri dan Purnami, 2019. Peran Kepuasan Memediasi Customer Relationship Management Terhadap Loyalitas Nasabah Bank Mega Cabang Sunset Road Kuta.

Riduwan dan Kuncoro, 2014. Cara Menggunakan dan Memakai Analisis Jalur (Path Analysis), Bandung: CV. Alfabeta.

Rudy Suryanto, SE., M.Acc., AK., CA, 2018. Peta Jalan BUMDES SUKSES, Yogyakarta: PT. Syncore Indonesia.

Sugiyono. 2003. Metode Penelitian Bisnis. Edisi I, Bandung: Alfabeta.

Storbacka, Kaj dan Jarmo R. Lehtinen, 2001. Customer Relationship Management: Creating Competitive Advantage Through Win-win Relationship Strategies. McGraw-Hill. Singapore

Tjiptono, F, Gregorius, C dan andriana, d.2010. Pemasaran Strategik. Yogyakarta: Andi Fandy, 2002. Manajemen Jasa. Edisi II, Andi Offset, Yogyakarta 2008. Total Quality Service. Penerbit ANDI. Yogyakarta. 
Victor, Christian dkk. (2015). Pengaruh Customer Relationship Management dan Kepercayaan Terhadap Kepuasan Serta Dampaknya Terhadap Loyalitas Konsumen PT. Bank BCA TBK. Di Manado

Zeithalm, Valarrie A., Mary Jo Bitner D. Gremler (2006). Service Marketing. Integrating Stomer Focus Across The Firm, $4^{\text {th }}$ Edition,m International Edition. Singapore: McGraw-Hill. 